\title{
Using the balanced scorecard as a performance management tool in higher education
}

\author{
By Mark Anthony Camilleri ${ }^{1}$, University of Malta, Malta. \\ This is a prepublication version.
}

How to Cite: Camilleri, M.A. (2020). Using the balanced scorecard as a performance management tool in higher education. Management in Education. Forthcoming.

\begin{abstract}
This paper presents a critical review of the relevant literature on managerialism and performance management in higher education. Afterwards, it features an inductive research that involved semistructured interview sessions with academic members of staff. The interpretative study relied on the balanced scorecard's (BSC) approach as it appraised the participants' opinions and perceptions on their higher education institution's (HEI) customer, internal, organizational capacity and financial perspectives. The findings have revealed the strengths and weaknesses of using the BSC's financial and non-financial measures to assess the institutional performance and the productivity of individual employees. In sum, this research reported that ongoing performance conversations with academic employees will help HEI leaders to identify their institutions' value creating activities. This contribution implies that HEI leaders can utilize the BSC's comprehensive framework as a plausible, performance management tool to regularly evaluate whether their institution is: (i) delivering inclusive, student-centered, quality education; (ii) publishing high impact research; (iii) engaging with internal and external stakeholders; and (iv) improving its financial results, among other positive outcomes.
\end{abstract}

Keywords: Performance Management, Performance Measures, Performance Appraisal, Managerialism, balanced scorecard, Higher Education.

\footnotetext{
${ }^{1}$ Department of Corporate Communication, Faculty of Media and Knowledge Sciences, University of Malta, Malta. Email: mark.a.camilleri@um.edu.mt
} 


\section{Introduction}

The higher education institutions (HEIs) including universities, polytechnics, vocational and postsecondary schools, as well as profession-oriented institutions provide formal, tertiary education services that can lead to the award of academic degrees or professional certifications. Such educational institutions have long been subjected to rigorous quality evaluations to ensure that they consistently offer inclusive, student centred teaching as well as high impact research (Kivistö, Pekkola and Lyytinen, 2017; DeNisi and Smith, 2014; Geuna and Martin 2003; Kanji, Malek and Tambi, 1999). Many stakeholders, including prospective students and academics can refer to 'league tables' like the Times Higher Education (THE) and the QS World University Rankings, among others, to review the HEIs' performance through different metrics (Cappiello and Pedrini, 2017; Decramer, Smolders and Vanderstraeten 2013; Deem 1998; Athanassopoulos and Shale, 1997).

Therefore, HEIs need to adapt to ongoing trends and developments in their macro and micro environments as they are expected to deal with political, economic, social and technological influences (Marginson, 2013; 2001; Deem, Mok and Lucas, 2008; Olssen and Peters, 2005; Etzkowitz, Webster, Gebhardt and Terra, 2000; Deem, 1998). At the same time, they need to capitalize on any available opportunities, including resources, competences and capabilities, to deliver high quality, student-centered education (Decramer, Smolders and Vanderstraeten, 2013; Welch, 2007; Billing, 2004; McKenzie and Schweitzer, 2001; Dilts, Haber, Bialik and Haber, 1994). Several universities are increasingly gathering information on value-added activities as they strive to improve their performance (Beard, 2010). Their leaders should be in a position to answer these important questions: What is the mission and vision of their institution? How is their institution offering value to its students and to society at large? Is their institution financially 
viable? Is their HEI using its scarce resources effectively, in terms of intellectual capital, technology and infrastructures? Are there any management tools that are employed in the realms of business that may be used to improve the leadership of the HEI? Very often, businesses are relying on goal-oriented processes, including performance management to measure and improve the value of an organization through regular reviews of individual employees or of teams (DeNisi and Pritchard, 2014; 2006; Kaplan and Norton, 1992; 1995). Similarly, the HEIs' underlying objective is to stimulate the productivity of their human resources (Brewer and Brewer, 2010; Smeenk, Teelken, Eisinga and Doorewaard, 2008).

HEIs have introduced managerial approaches and embraced performance management frameworks to enhance their international status (Cappiello and Pedrini, 2017; Waring, 2013; Lo, 2009). HEI leaders are increasingly evaluating their human resources, competences and capabilities as they invest in technological innovations and infrastructures to support them (Teelken, 2012; Deem and Brehony, 2005; Deem, 1998). Their performance management activities are rooted in their organizational capacity toward achieving continuous improvements in their operations (Brewer and Brewer, 2010; Irwin, 2008; Smeenk et al., 2008). Hence, HEIs are encouraged to appraise their academics through the lenses of quality research, teaching and on their ability to forge relationships with stakeholders (Kohoutek, Veiga, Rosa and Sarrico, 2018; Camilleri, 2015; De Cramer et al., 2013). The organizations' capacity (for innovation and learning), internal processes as well as their stakeholder engagement are an integral part for the universities' performance management (Taylor and Baines, 2012; Beard, 2009). This argumentation is synonymous with Kaplan and Norton's (1992) balanced scorecard (BSC) strategic management perspectives that have been widely popularized in business circles. 
The basic premise of BSC's approach is that practitioners could develop a comprehensive set of performance measures, or predictors to capture value-creating activities. BSC's financial, customer (student), internal processes, and organizational capacity perspectives ought to be aligned with the organization's vision, mission and strategic goals, thus enabling managers to monitor and revise their strategies (Camilleri and Camilleri, 2018; Waring, 2013; Kaplan and Norton, 1995). Its proponents argue that BSC establishes objectives for these perspectives, and then selects appropriate measures to track their progress toward attaining these goals. Thus, BSC can support the performance management of HEIs; as its monitoring systems enable them to become more efficient and productive (Witte and López-Torres, 2017; Rollings, 2011; Umashankar and Dutta, 2007; Welch, 1998).

\section{The Research Questions}

The rationale of this paper is to further consolidate the subject of performance management within the higher education literature (Taylor and Baines, 2012; Teelken, 2012; Wu et al., 2011; Beard, 2009; Cullen et al., 2003). This contribution is a useful complement to the latest review papers and empirical studies that have sought to explore the universities' managerialism. It adds value to the extant theoretical underpinnings as it features an inductive research that has explored the academic employees' opinions and perceptions on their institution's performance management and appraisal systems. The methodology relied on Kaplan and Norton's (1992) BSC's comprehensive framework and its customer, internal, organizational capacity and financial perspectives to capture the HEI's value-creating activities. Therefore, this study's focused research questions are: What are the strengths and weaknesses of adopting the BSC approach in the higher educational context? How can the HEI leaders improve their institutional performance as well as their employees' productivity? 


\section{The "Managerialism" in Higher Education}

HEIs are competing in a global marketplace, particularly those which are operating in the contexts of neoliberal policymaking (Fadeeva and Mochizuki, 2010; Deem et al., 2008; Olssen and Peters, 2005; Bleiklie, 2001). Several universities are characterized by their de-centralized leadership as they operate with budget constraints (Smeenk, Teelken, Eisinga and Doorewaard, 2008; Bleiklie, 2001). Notwithstanding, their stakeholders expect their increased accountability and quality assurance, in terms of their efficiency, economy and effectiveness (Camilleri, 2018; Witte and López-Torres, 2017; Smeek et al., 2008). Hence, HEIs set norms, standards, benchmarks, and quality controls to measure their performance; as they are increasingly market-led and customerdriven (Jauhiainen, Jauhiainen, Laiho and Lehto, 2015; Billing, 2004; Etzkowitz, et al., 2000). Specifically, the universities' performance is having a positive effect on the economic development of societies; through the provision of inclusive, democratized access to quality education and high impact research (Camilleri, 2019a,b; Arnesen \& Lundahl, 2006). Moreover, the educational institutions are also expected to forge strong relationships with marketplace stakeholders, including business and industry (Waring, 2013).

As a result, many universities have adapted, or are trying to adapt to the changing environment as they re-structure their organization and put more emphasis on improving their organizational performance. These developments have inevitably led to the emergence of bureaucratic procedures and processes (Jauhiainen et al., 2015). HEIs have even started using the corporate language as they formulate plans, set objectives, and use performance management criteria to control their resources (Smeenk et al., 2008; Ball, 2003). For instance, the Finnish universities have introduced new steering mechanisms, including the performance systems in budgeting, organizational reforms, management methods and salary systems (Jauhiainen et al., 2015). Previously, Welch 
(2007) noted that HEIs were adopting new modes of governance, organizational forms, management styles, and values that were prevalent in the private business sector. The logic behind these new managerial reforms was to improve the HEIs' value for money principles (Waring, 2013; Deem, 1998). Therefore, the financing of HEIs is a crucial element in an imperfectly competitive, quasi-market model (Marginson, 2013; Olssen and Peters, 2005; Enders, 2004; Dill, 1997).

Academic commentators frequently suggest that the managerial strategies, structures, and values that belong to the 'private sector' are leading to significant improvements in the HEIs' performance (Waring, 2013; Teelken, 2012; Deem and Brehony, 2005; Deem, 1998). On the other hand, critics argue that the 'managerial' universities are focusing on human resource management (HRM) practices that affect the quality of their employees' job performance (Smeenk et al., 2008). Very often, HEIs are employing bureaucratic procedures involving time-consuming activities that could otherwise have been invested in research activities and / or to enhance teaching programs. The HEIs' management agenda is actually imposed on the academics' norms of conduct and on their professional behaviors. Therefore, the universities' leadership can affect the employees' autonomies as they are expected to comply with their employers' requirements (Deem and Brehony, 2005). Smeenk et al. (2008) posited that this contentious issue may lead to perennial conflicts between the employees' values and their university leaders' managerial values; resulting in lower organizational commitment and reduced productivities.

The HEIs' managerial model has led to a shift in the balance of power from the academics to their leaders as the universities have developed quality assurance systems to monitor and control their academic employees' performance (Camilleri, 2018; Cardoso, Tavares and Sin, 2015). This trend towards managerialism can be perceived as a lack of trust in the academic community. However, the rationale behind managerialism is to foster a performative culture among members of staff, as 
universities need to respond to increased competitive pressures for resources, competences and capabilities (Decramer et al., 2013; Marginson, 2006; 2001; Enders, 2004). These issues have changed the HEIs' academic cultures and norms in an unprecedented way (Chou and Chan, 2016; Marginson, 2013).

HEIs have resorted to the utilization of measures and key performance indicators to improve their global visibility. Their intention is to raise their institutions' profile by using metrics that measure productivity. Many universities have developed their own performance measures or followed frameworks that monitor the productivity of academic members of staff (Taylor and Baines, 2012). Very often, their objective is to audit their academic employees' work. However, their work cannot always be quantified and measured in objective performance evaluations. For instance, Waring (2013) argued that academic employees are expected to comply with their employers' performance appraisals (PAs) and their form-filling exercises. The rationale behind the use of PAs is to measure the employees' productivity in the form of quantifiable performance criteria. Hence, the PA is deemed as a vital element for the evaluation of the employees' performance (Kivistö et al., 2017; Dilts et al., 1994). The PA can be used as part of a holistic performance management approach that measures the academics' teaching, research and outreach. This performance management tool can possibly determine the employees' retention, promotion, tenure as well as salary increments (Subbaye, 2018; Ramsden, 1991).

Therefore, PAs ought to be clear and fair. Their administration should involve consistent, rational procedures that make use of appropriate standards. The management's evaluation of the employees' performance should be based on tangible evidence. In a similar vein, the employees need to be informed of what is expected from them (Dilts et al., 1994). They should also be knowledgeable about due processes for appeal arising from adverse evaluations, as well as on 
grievance procedures, if any (Camilleri, 2018). In recent years; the value of the annual performance appraisals (PAs) has increasingly been challenged in favor of more regular 'performance conversations' (Aguinis, 2013; Herdlein, Kukemelk and Türk, 2008). Therefore, regular performance feedback or the frequent appraisal of employees still remain a crucial aspect of the performance management cycle. Pace (2015) reported that the PA was used to develop the employees' skills, rather than for administrative decisions. In a similar vein, the University of Texas (2019) HR page suggests that the appraisers" role is "to set expectations, gather data, and provide ongoing feedback to employees, to assist them in utilizing their skills, expertise and ideas in a way that produces results". However, a thorough literature review suggests that there are diverging views among academia and practitioners on the role of the annual PA, the form it should take, and on its effectiveness in the realms of higher education (Herdlein et al., 2008; DeNisi and Pritchard, 2006).

\section{The Performance Management Frameworks}

The HEIs' evaluative systems may include an analysis of the respective universities' stated intentions, peer opinions, government norms and comparisons, primary procedures from 'selfevaluation' through external peer review. These metrics can be drawn from published indicators and ratings, among other frameworks (Billing, 2004). Their performance evaluations can be either internally or externally driven (Cappiello and Pedrini, 2017). The internally driven appraisal systems put more emphasis on self-evaluation and self-regulatory activities (Baxter, 2017; Bednall, Sanders and Runhaar, 2014; Dilts et al., 1994). Alternatively, the externally driven evaluative frameworks may involve appraisal interviews that assess the quality of the employees' performance in relation to pre-established criteria (DeNisi and Pritchard, 2006; Cederblom, 1982). 
Many countries, including the European Union (EU) states have passed relevant legislation, regulatory standards and guidelines for the HEIs' quality assurance (Baxter, 2017), and for the performance evaluations of their members of staff (Kohoutek et al., 2018; Cardoso et al., 2015; Bleiklie, 2001). Of course, the academic employees' performance is usually evaluated against their employers' priorities, commitments, and aims; by using relevant international benchmarks and targets (Lo, 2009). The academics are usually appraised on their research impact, teaching activities and outreach (QS Ranking, 2019; THE, 2019). Their academic services, including their teaching resources, administrative support, and research output all serve as performance indicators that can contribute to the reputation and standing of the HEI that employs them (Geuna and Martin, 2003).

Notwithstanding, several universities have restructured their faculties and departments to enhance their research capabilities. Their intention is to improve their institutional performance in global rankings (Lo, 2014). Therefore, HEIs recruit academics who are prolific authors that publish highimpact research with numerous citations in peer reviewed journals (Wood and Salt, 2018; Camilleri and Camilleri, 2019). They may prefer researchers with scientific or quantitative backgrounds, regardless of their teaching experience (Chou and Chan, 2016). These universities are prioritizing research and promoting their academics' publications to the detriment of university teaching. Thus, the academics' contributions in key international journals is the predominant criterion that is used to judge the quality of academia (Billing, 2004). For this reason, the vast majority of scholars are using the English language as a vehicle to publish their research in reputable, high impact journals (Chou and Chan, 2016). Hence, the quantity and quality of their research ought to be evaluated through a number of criteria (Lo, 2014; 2011; Dill and Soo, 2005).

University ranking sites, including (THE) and the QS Rankings, among others, use performance indicators to classify and measure the quality and status of HEIs. This would involve the gathering 
and analysis of survey data from academic stakeholders. THE and QS, among others clearly define the measures, their relative weight, and the processes by which the quantitative data is collected (Dill and Soo, 2005). The Academic Ranking of World Universities (ARWU) relies on publicationfocused indicators as 60 percent of its weighting is assigned to the respective university's research output. Therefore, these university ranking exercises are surely affecting the policies, cultures and behaviors of HEIs and of their academics (Wood and Salt, 2018; De Cramer et al., 2013; Lo, 2013). For instance, the performance indicators directly encourage the recruitment of international faculty and students. Other examples of quantitative metrics include the students' enrolment ratios, graduate rates, student drop-out rates, the students' continuation of studies at the next academic level, and the employability index of graduates, among others. Moreover, qualitative indicators can also provide insightful data on the students' opinions and perceptions about their learning environment. The HEIs could evaluate the students' satisfaction with teaching; satisfaction with research opportunities and training; perceptions of international and public engagement opportunities; ease of taking courses across boundaries, and may also determine whether there are administrative / bureaucratic barriers for them (Kivistö et al., 2017; Jauhiainen et al., 2015; Ramsden, 1991). Hence, HEIs ought to continuously re-examine their strategic priorities and initiatives. It is in their interest to regularly analyze their performance management frameworks through financial and non-financial indicators, in order to assess the productivity of their human resources. Therefore, they should regularly review educational programs and course curricula (Kohoutek et al., 2018; Brewer and Brewer, 2010). On a faculty level, the university leaders ought to keep a track record of changes in the size of departments; age and distribution of academic employees; diversity of students and staff, in terms of gender, race and ethnicity, et cetera. In addition, faculties could examine discipline-specific rankings; and determine the expenditures per academic member of staff, among other options (Camilleri, 2018). 


\section{The balanced scorecard}

The balanced scorecard (BSC) was first introduced by Kaplan and Norton (1992) in their highly cited article, entitled "The Balanced Scorecard: Measures that Drive Performance". BSC is an integrated results-oriented, performance management tool, consisting of financial and nonfinancial measures that link the organizations' mission, core values, and vision for the future with strategies, targets, and initiatives that are designed to bring continuous improvements (Taylor and Baines, 2012; Wu, Lin and Chang, 2011; Beard, 2009; Umashankar and Dutta, 2007; Cullen, Joyce, Hassall and Broadbent, 2003; Kaplan and Norton, 1992). Its four performance indicators play an important role in translating strategy into action; and can be utilized to evaluate the performance of HEIs. BSC provides a balanced performance management system as it comprises a set of performance indices that can assess different organizational perspectives (Taylor and Baines, 2012). For BSC, the financial perspective is a core performance measure. However, the other three perspectives namely: customer (or stakeholder), organizational capacity and internal process ought to be considered in the performance evaluations of HEIs, as reported in Table 1: 


\section{Table 1.}

The balanced scorecard approach in higher education

\begin{tabular}{|c|c|c|}
\hline Perspective & Question & Explanation \\
\hline $\begin{array}{l}\text { 1. Customer } \\
\text { (the students, alumni, parents, } \\
\text { business, policy makers in } \\
\text { education, society at large) }\end{array}$ & $\begin{array}{l}\text { What do HEI customers } \\
\text { need and want? }\end{array}$ & $\begin{array}{l}\text { This perspective views } \\
\text { organizational performance } \\
\text { from the point of view of its } \\
\text { customers. It focuses on the } \\
\text { provision of courses to } \\
\text { students as well as to } \\
\text { employed individuals who } \\
\text { are furthering their } \\
\text { education. It involves } \\
\text { outreach and collaborative } \\
\text { agreements with external } \\
\text { stakeholders (e.g. } \\
\text { government, business and } \\
\text { industry) }\end{array}$ \\
\hline $\begin{array}{l}\text { 2. Internal } \\
\text { (the academic and } \\
\text { administrative members of } \\
\text { staff) }\end{array}$ & $\begin{array}{l}\text { What are the HEIs' internal } \\
\text { processes that can enhance } \\
\text { the educational objectives? }\end{array}$ & $\begin{array}{l}\text { This perspective views the } \\
\text { educational institutions' } \\
\text { internal operations. It } \\
\text { involves examining the } \\
\text { delivery of student-centered, } \\
\text { quality education, individual } \\
\text { research output, engagement } \\
\text { with trade and professional } \\
\text { organizations. It also } \\
\text { considers the internal } \\
\text { services, resources and } \\
\text { facilities that are used by the } \\
\text { employees. }\end{array}$ \\
\hline $\begin{array}{l}\text { 3. Organizational Capacity } \\
\text { (Innovation and the } \\
\text { continuous professional } \\
\text { development of academic and } \\
\text { non-academic employees; } \\
\text { investments in competences, } \\
\text { capabilities and resources) }\end{array}$ & $\begin{array}{l}\text { How can HEI improve their } \\
\text { organizational learning to } \\
\text { create value? }\end{array}$ & $\begin{array}{l}\text { This perspective views } \\
\text { organizational performance } \\
\text { through the lenses of human } \\
\text { capital, infrastructure, } \\
\text { technology, culture and } \\
\text { other capacities that are key } \\
\text { to the creation and } \\
\text { dissemination of knowledge. } \\
\text { It considers the educational } \\
\text { institutions' research output } \\
\text { (as a whole), and its capacity } \\
\text { to maintain a competitive } \\
\text { position through the } \\
\text { identification of training } \\
\text { needs of the members of } \\
\text { staff. }\end{array}$ \\
\hline 4. Financial & $\begin{array}{l}\text { How can HEIs improve } \\
\text { their financial } \\
\text { performance? How can } \\
\text { they use their financial } \\
\text { resources in an effective } \\
\text { manner? }\end{array}$ & $\begin{array}{l}\text { This perspective considers } \\
\text { the organization's financial } \\
\text { performance and its } \\
\text { productive use of resources. } \\
\text { It covers traditional measures } \\
\text { such as sales revenue, costs / } \\
\text { expenses, return on } \\
\text { investment and profitability. }\end{array}$ \\
\hline
\end{tabular}


Cullen et al. (2003) suggested that the UK's Higher Education Funding Council for England (HEFCE), the Scottish Funding Council (SHEFC), the Higher Education Funding Council for Wales (HEFCW), as well as the Department for Employment and Learning (DELNI) have incorporated the BSC's targets in their Research Excellence Framework. Furthermore, other HEI targets, including: the students' completion rates, the research impact of universities, collaborative partnerships with business and industry, among others, are key metrics that are increasingly being used in international benchmarking exercises, like the European Quality Improvement System (EQUIS), among others. Moreover, BSC can be used to measure the academic employees' commitment towards their employer (Umashankar and Dutta, 2007; McKenzie, and Schweitzer, 2001). Notwithstanding, Wu, Lin and Chang (2011) contended that the BSC's “organizational capacity" is related to the employee development, innovation and learning. Hence the measurement of the HEIs' intangible assets, including their intellectual capital is affected by other perspectives, including the financial one (Taylor and Baines, 2012). Table 2 summarizes some of the strengths and weaknesses of the balanced scorecard. 
Table 2.

A critical appraisal of the balanced scorecard

\begin{tabular}{|l|l|}
\hline Strengths & Weaknesses \\
\hline $\begin{array}{l}\text { The four perspectives provide a balanced, } \\
\text { multi-channel approach to measuring the } \\
\text { organizations' performance. }\end{array}$ & $\begin{array}{l}\text { The implementation of BSC necessitates the } \\
\text { use of scarce resources. }\end{array}$ \\
\hline $\begin{array}{l}\text { The four inter-dependent perspectives are } \\
\text { characterized by a flow of information and } \\
\text { communications among individuals and } \\
\text { departments. }\end{array}$ & $\begin{array}{l}\text { The four perspectives are interlinked. They } \\
\text { require the involvement of all employees for } \\
\text { continuous improvements in performance } \\
\text { management. }\end{array}$ \\
\hline $\begin{array}{l}\text { The four perspectives offer the } \\
\text { comprehensive measurement of financial } \\
\text { and non-financial performance. }\end{array}$ & $\begin{array}{l}\text { It may prove difficult to find a trade-off } \\
\text { between the financial and non-financial } \\
\text { measures }\end{array}$ \\
\hline $\begin{array}{l}\text { The BSC's metrics feature meaningful terms, } \\
\text { that are easily understood by the members of } \\
\text { staff. }\end{array}$ & $\begin{array}{l}\text { The gathering of data from the performance } \\
\text { evaluations may result in an information } \\
\text { overload from the past performance. }\end{array}$ \\
\hline $\begin{array}{l}\text { BSC balances short-term and long-term } \\
\text { strategies with a focus on organizational } \\
\text { outcomes. }\end{array}$ & $\begin{array}{l}\text { It may be difficult to translate long-term } \\
\text { goals into reasonable short-term targets }\end{array}$ \\
\hline $\begin{array}{l}\text { BSC's measures are closely related to } \\
\text { corporate strategy, the organizations' goals } \\
\text { and objectives are linked with the } \\
\text { competences of human resources and their } \\
\text { capabilities. }\end{array}$ & $\begin{array}{l}\text { BSC does not focus on the political, } \\
\text { economic / competitive, social and } \\
\text { technological issues that can have an effect. } \\
\text { on the performance management of HEIs. }\end{array}$ \\
\hline
\end{tabular}

BSC is widely used to appraise the financial and non-financial performance of businesses and public service organizations including HEIs. Many HEI leaders are increasingly following business-like approaches as they are expected to operate in a quasi-market environment (Marginson, 2013). They need to scan their macro environment to be knowledgeable about the opportunities and threats from the political, economic, social and technological factors. Moreover, 
they have to regularly analyze their microenvironment by evaluating their strengths and weaknesses. Hence, several HEIs are increasingly appraising their employees as they assess their performance on a regular basis. They may even decide to take remedial actions when necessary. Therefore, BSC can also be employed by HEIs to improve their academic employees' productivity levels (Marginson, 2013; 2000).

\section{Research Design and Methodology}

Relevant academic literature in educational research has previously adopted Kaplan and Norton's (1992) BSC (Taylor and Baines, 2012; Wu et al., 2011; Beard, 2009; Cullen et al., 2003) to investigate the performance management in HEIs. Therefore, this contribution adds value to the extant literature as it investigates the performance management and appraisal system of a higher education service provider from the Southern European context. The researcher has used a phenomenological methodological approach during the data capture and analysis stages, to search for a deeper understanding of the university institution's PA processes and procedures that were intended to increase its organizational efficiency, performance, authority and accountability. The data was gathered from the informants who "have had experiences relating to the phenomenon to be researched" (Groenewald, 2004, p45). This has allowed the researcher to interpret the academic employees' (i.e. the appraisees') perceptions on quality, student-centered education (the customers' perspective), the evaluation of their performance, in terms of teaching and their preparation of high-impact research (i.e. the internal perspective), continuous professional development, training and career growth (i.e. the organizational capacity perspective) and on their HEI's financial results and its related capital investments in human resources, technology and infrastructures (i.e. the financial perspective) (Camilleri, 2019b). 
The researcher has utilized the BSC's comprehensive set of financial and non-financial measures as performance indicators, or predictors in order to capture value-creating activities in the context of an HEI. A critical factor for the effective usage of the BSC approach is the alignment of its four perspectives with the organization's vision and strategic objectives (Taylor and Baines, 2012; Kaplan and Norton, 1995). Therefore, this study queried about the HEIs' strategic elements such as its mission (i.e. the organization's purpose), vision (and aspirations), core values, strategic focus areas (including themes, results and/or goals) and the more operational elements such as objectives (and continuous improvement activities), or key performance indicators that are intended to track strategic performance targets (i.e. the desired level of performance), and initiatives (and projects that will help organizations to reach their targets). The researcher has investigated the HEIs' performance through the lens of the BSCs' stakeholder (or customer), internal, organizational capacity and financial perspectives.

\section{The Research Context}

The HEI's educational leaders appraise the performance of their academic and administrative employees on an annual basis to encourage self-reflection and development. Generally, the academics are assessed on three areas of performance, including: (i) lecturing, mentoring and tutoring, (ii) research, and (iii) administration. Thus, the educational leaders utilize both qualitative and quantitative measures to evaluate their academic employees' performance on their teaching, publications and administrative tasks. Every HEI department assists its employees in identifying their personal and professional development needs by providing them supportive HRM frameworks and performance management criteria. 
The PA provides the basis for the evaluation of the academics' performance and merit. Its quantitative ratings and qualitative reviews involve an annual assessment of the individuals' productivity. In this case, the educational leaders use a consistent performance management process that serves the interests of their institution's human resource management, corporate governance and employee development (Heywood, Jirjahn and Struewing, 2017; Brewer and Brewer, 2010; Ramsden, 1991). The staff appraisal is one of their HEI's strategic HRM practices as it enables the head of departments (HODs) to identify the training and development needs of their employees. During the appraisal, the HODs (or designated appraisers) discuss with the individual employees their personal goals, tasks and aspirations, whilst assisting them with the identification of professional development needs and tasks. S/he will maintain appropriate written records of each appraisal meeting. The appraisal of the educators (including lecturers and teaching associates) will usually involve a classroom observation. The HODs (or designated appraiser) may also evaluate the students' feedback on the educators' courses (McKenzie and Schweitzer, 2001). Their scope is to identify and address any areas of concern.

The HEIs' performance management and its evaluation process is a collaborative appraiser / employee (appraisee) process that starts with the identification of the individual employee's duties and responsibilities. This information can also be retrieved from the job description from the contract of employment. This document includes relevant details on how individual employees are expected to meet their employer's pre-defined goals and objectives.

Every year, the HEI leaders rely on a combination of quantitative and qualitative performance management and appraisal systems. They use rating scales as well as "collaborative methods", where the employees can communicate to their employer. This feedback is used by the appraiser 
to evaluate the employees' performance during the appraisal year. It also offers the appraisees the chance to review their own accomplishments, and to actively participate in their organization's goal setting process. This way, they can identify their strengths and any areas of performance (including behaviors, conduct and results) where they could improve. The academic employees are also encouraged to discuss their expectations for the following year. Afterwards, the appraisers will mark the appraisal form with their quantitative ratings and qualitative feedback following the informal meeting with the appraisees.

The appraisee has the right to reply to the appraiser's ratings and remarks in writing. Eventually, both of them will sign the performance form to acknowledge that their PA has been discussed. Finally, the HEI leaders will retain the original signed form and will provide the appraisee with a copy of the signed form. Hence, the performance form will be kept in the human resources department where there is the individual employee's file. In addition, the appraiser(s) may also include any written justification for their performance scores (or for their remarks).

\section{Capturing and Interpreting the Qualitative Findings}

A purposive sampling technique was used to locate the informants for this qualitative study (Groenewald, 2004). An email was disseminated amongst academic colleagues who worked in the same university faculty. It called for their expressions of interest to participate in an inductive research about their performance management and appraisal. The prospective research participants were duly informed about the rationale of this study, and on its aims and objectives. After two weeks, there were eighteen academic members of staff who had given their informed consent to participate in this study. Hence, the researcher assured the research participants that their identity 
shall remain anonymous and confidential. Table 3 presents a demographic profile of the research participants.

Table 3.

The Demographic Profile of the Interviewees

\begin{tabular}{|l|c|}
\hline Gender & $\mathrm{N}$ \\
\hline Female & 11 \\
\hline Male & 7 \\
\hline N/A & 0 \\
\hline Total & $\mathbf{1 8}$ \\
\hline & \\
\hline Job Designation & $\mathrm{N}$ \\
\hline Assistant Lecturer & 6 \\
\hline Lecturer & 5 \\
\hline Senior Lecturer & 3 \\
\hline A / Professor & 4 \\
\hline Professor & 0 \\
\hline Other & 0 \\
\hline Total & $\mathbf{1 8}$ \\
\hline
\end{tabular}

\begin{tabular}{|l|c|}
\hline Level of Education & $\mathrm{N}$ \\
\hline Bachelor & 0 \\
\hline Master & 6 \\
\hline Doctorate & 12 \\
\hline Other & 0 \\
\hline Total & $\mathbf{1 8}$ \\
\hline & \\
\hline Work Experience & $\mathrm{N}$ \\
\hline$<5$ years & 12 \\
\hline$>5$ years and $<10$ years & 4 \\
\hline$>10$ years and $<20$ years & 1 \\
\hline$>20$ years & 1 \\
\hline Total & $\mathbf{1 8}$ \\
\hline & \\
\hline
\end{tabular}

The interpretative data was gathered through face-to-face, semi-structured interview sessions. This phenomenological research allowed the researcher to investigate the participants' in-depth opinions, perceptions and beliefs toward their HEI performance management systems. The interview guiding questions are enclosed in Appendix A.

During the data gathering process, the researcher had an opportunity to observe the interviewees' environmental setting, the organization's culture and structure, the HEI leaders' management 
styles, and the academic employees' attitudes toward them, among other variables. He annotated the research participants' observations, ideas, impressions and interpretations on anything that shed light on the context, in reflective memos. The data was transcribed within a few minutes after the interview sessions. The interviewees received a copy of the researcher's textual annotations and of their audio recordings. This way, the researcher confirmed that the gathered data truly reflected his informants' perspectives (Groenewald, 2004). Notwithstanding, this study has followed Lincoln and Guba's (1985) rigorous principles that establish the trustworthiness of qualitative research.

\section{The Findings}

\section{The Benefits of Performance Evaluations}

The HEI's leaders use a consistent performance management tool that serves the interests of their organization's human resource management in terms of assessing their academic employees' productivity, as they evaluate their ability to deliver quality education, and to publish high-impact research in peer-reviewed journals. Moreover, the organization's PA also provides the opportunity to identify any investment needs in terms of resources, technologies and infrastructures. Therefore, the performance management and appraisal exercise included financial and non-financial measures. It also balanced short-term objectives with long-term strategies in order to improve the HEI's organizational outcomes (Dinham, 2005).

The academic literature has often discussed how the successful implementation of the PA instrument relies on supervisor-employee relationships (Salanova, Agut and Peiró, 2005). The appraisers are expected to create a "common ground" with their subordinates throughout the year. This enables them to build a social foundation of aligned efforts that permeate the positive reactions toward the PA systems. Thus, the PA exercise could be considered as a performance management 
tool that is intended to improve the communication within the organization, between the academic employees and their educational leaders. Therefore, the PA instrument could lead to continuous improvements in the workplace environment (Kaplan and Norton, 1995). In this case, the majority of the research participants agreed that the PA was focused on improving their extant working relationships with their HEI leaders.

Four of the informants who have been engaged for less than five years, admitted that the PA has helped them clarify their work goals; as it supported them in improving their individual performance (Salanova et al., 2005). Two senior lecturers contended that their educational leaders were recognizing and acknowledging their progress, year after year. Another interviewee pointed out that; "the PA makes academic staff more accountable to their students and authorities". These responses resonate with the extant literature on the subject. One of the main functions of PA should be the identification and achievement of work goals rather than just assessing performance (DeNisi and Smith, 2014; Salanova et al., 2005). In a similar vein, eight interviewees held that the PA provided them with insightful feedback from their appraisers. This has led them to increase their morale, job motivation and commitment (Kuvaas, 2006; Gagné and Deci 2005). Several academic members of staff who participated in this study have also communicated to the researcher that they expected their HEI leaders to acknowledge their work output. A few informants also contended that they considered recognition as a form of reward. This finding was also reflected in other literature (Kuvaas, 2006). The informants maintained that the PA exercise has improved the organizational communication. One of the informants suggested, "PA should be used to develop and support us on an ongoing basis rather than being a one-off session, once a year". She believed that the PA should be a continuous process as a means of improving communication between the academic employees and their HEI leaders. 
Other informants discussed other issues, including the allocation of an annual performance bonus; the identification of specific individuals for future promotion and on the use of PA to monitor the employees' individual performance (Subbaye, 2018). Hence, the informants suggested that the PA should support outstanding members of staff in their career development, and to reward their efforts, in a commensurate manner. They argued that the PA instrument can be considered as an HRM tool as it could lead to continuous improvements in their workplace environment.

\section{Some Aspects of Concern with Performance Evaluations}

Generally, the informants claimed that they looked forward to their annual performance appraisal. However, they argued that the PA involved the collection of data on various aspects of their academic work, including the listings of their research publications. The participants admitted that the performance management of their student-centered teaching and of their societal engagement were harder to quantify and measure. The participants suggested that the annual PA exercise had its inherent weaknesses:

Four informants held that they did not feel that they owned their PA process. This finding was also reported in relevant academic literature that has emphasized how the PA exercise ought to be part of a wider performance management strategy (DeNisi and Smith, 2014; Herdlein et al., 2008; Umashankar, and Dutta, 2007). The PA system may be ineffective unless it is linked to other performance-enhancing policies. Arguably, when the PA is used in isolation, it may not yield the desired outcomes (Dinham, 2005). In one of the respondent's own words, “...the PA must form part of the organizational culture, rather than being considered as something that needs to be got over and done with". This interviewee claimed that "not much time was being devoted to the execution of the PA exercise", as "the lecturers did not feel that they own their PA process". 
Similarly, other interviewees claimed that the PA has become an annual administrative task for their HEI leaders.

There were two informants who pointed out that the measurement of performance is subjective. They argued that the appraisers' negative criticism can lead to employee demotivation, turn-over intention, as well as unproductive behaviors from the employees' part (Kuvaas, 2006; Gagné and Deci, 2005). Most of the interviewees were in disarray when the interviewer questioned them if they thought that the PA instrument could be used to inform their HEI leaders on harder HR disciplinary decisions, or on issues relating to retention, termination of employment. In these cases, two other informants have voiced their concerns over the subjectivity of the PA procedure. They argued that there may be specific situations where the appraisers' decisions could be agreed upon by the appraisee. Alternatively, they may be contested, leading to conflicts and grievances. Another informant iterated that the PA may cause unnecessary tension among employees if they believed that it is being used by HR to take 'hard' decisions. In the main, the interviewees pointed out that for the time being, the appraisers did not have the authority to implement contentious HR decisions that will affect their future employment prospects, or their take-home pay.

The participants agreed that the PA process ought to focus on development of employees by establishing future objectives, rather than merely assessing their past performance. For instance, five respondents suggested that the PA instrument was not being adopted to identify the training requirements of the academic employees, to keep them up to date with the latest technologies and resources. 


\section{Conclusions}

The findings from this research suggest that the HEI's performance management systems and their outcomes are dependent on the skill and on the predisposition on the part of assessors who provide their constructive criticism and key recommendations on BSC's four perspectives (see Appendix A). The appraisers are entrusted to set out clear objectives to the appraisees, and to measure their productivity and effectiveness in their workplace environment. At the same time, they are expected to identify the employees' strengths as well as their weak areas that require further improvement. The appraisers are in a position to nurture the talent of their colleagues as they determine the continuous professional development needs of their organization. Thus, evaluators also require adequate training on how to conduct the effective appraisals of their colleagues. This training should instruct them how to rate appraisees. It could inform them how to conduct fair appraisals and unbiased reviews. It can also be an opportunity for them to improve their relationships with other employees, as good appraisal systems involve positive reinforcement and constructive feedback.

Arguably, the PA exercise is an excellent opportunity for the appraiser and the appraisee to engage in a fruitful dialogue. Yet, this evaluative instrument should never substitute the ongoing communications and coaching that is expected from the HEI leaders, on a day-to-day basis. Such performance management systems are intended to inform the academic employees of how they stand with their employer on factors, including; job-related criteria e.g. research output. Assessors ought to clarify what criteria has been used to evaluate the appraisees' productivity. Eventually, this would result in positive outcomes that will translate to significant improvements in terms of the academic employees' performance and of their institution. In sum, this research implied that the PA process has informed the HEI leaders about their academic employees' performance and 
productivity. It postulated that its successful execution could have positive effects on the appraisees' motivation and job satisfaction.

In sum, this contribution has included a critical review of the literature where it reported about the increased establishment of managerialism in higher education. This development has inevitably led to an increased reliance of appropriate performance management and appraisal of academic members of staff. Hence, the researcher relied on the BSC's four perspectives to examine the academic employees' perceptions of the PA process in a higher educational setting.

This research suggests that BSC enables the HEI leaders to consider financial and non-financial metrics. Its comprehensive measures allow them to consider different aspects of the academic employees' performance. Specifically, the customer perspective evaluates the HEI's performance from the point of view of its students, parents, and society at large. The internal perspective is concerned with the academic employees' performance, in terms of measuring their research output in quantitative terms (e.g. the number of papers published in high impact journals), and their administrative work. The academics may be appraised for their contribution in academic conferences or in industry gatherings. They may be evaluated on their direct contribution to society, culture and the economy at large. The organizational capacity perspective is related to innovation and learning. It involves the scrutiny of the academics' competences, capabilities and resources (Irwin, 2008; Salanova et al., 2005). This perspective examines the HEIs' performance through the lenses of human capital, infrastructure, technology, and other capacities that are necessary for the creation and dissemination of knowledge. Moreover, BSC's financial perspective involves an analysis of the HEI's past financial performance, and the budgeting procedures for the allocations of funds and resources (Geuna and Martin, 2003). 


\section{The Way Forward}

The findings from this research suggest that BSC holds great potential to create value in higher education. BSC is a strategy-based performance management system that can enable HEIs to clarify their missions and visions. Its balanced perspectives can improve the performance of HEIs, as it identifies what really matters to customers (students) and stakeholders. BSC analyses the past and current performance. However, its non-financial performance measures, its objectives and targets are far reaching, as they provide reasonable guidance for the future.

BSC's key-performance indicators and their integration into HEI's strategic planning are intended to enhance the quality and status of universities, in terms of; (i) the delivery of customer-centric education, (ii) improving its research impact and (iii) increasing outreach with stakeholders, among other goals. Consequentially, the universities' successes in these areas could result in significant advances in international rankings. As a result, they will be in a position to attract more students and highly prolific academia.

This contribution opens-up future research avenues. Undoubtedly, there is scope for further research that explores how HEIs are utilizing the BSC performance management framework. Future studies can adopt other sampling frames, and observational research methodologies in different contexts. There is scope in conducting longitudinal research that investigates how BSC and its performance metrics are resulting in a quality higher education for the sustainability of universities. 


\section{Acknowledgements}

The author thanks the academic members of staff who participated in this study. He has appreciated the constructive remarks and suggestions of this journal's editor and of her reviewers.

\section{References}

Aguinis H (2013) Performance Management (Vol. 2). Boston, MA: Pearson.

Athanassopoulos AD and Shale E (1997). Assessing the comparative efficiency of higher education institutions in the UK by the means of data envelopment analysis. Education Economics, 5(2): 117-134.

Arnesen AL and Lundahl L. (2006) Still social and democratic? Inclusive education policies in the Nordic welfare states. Scandinavian Journal of Educational Research 50(3): 285-300.

Ball SJ (2003) The teacher's soul and the terrors of performativity. Journal of Education Policy 18(2): 215-228.

Baxter JA (2017) School Governor regulation in England's changing education landscape. Educational Management Administration and Leadership 45(1): 20-39.

Beard DF (2009) Successful applications of the balanced scorecard in higher education. Journal of Education for Business 84(5): 275-282.

Billing D (2004) International comparisons and trends in external quality assurance of higher education: Commonality or diversity? Higher Education 47(1): 113-137.

Bleiklie I (2001) Towards European convergence of higher education policy? Higher Education Management 13(3): 9-29.

Brewer PD and Brewer KL (2010) Knowledge management, human resource management, and higher education: a theoretical model. Journal of Education for Business 85(6): 330-335.

Camilleri, MA (2015) Valuing Stakeholder Engagement and Sustainability Reporting. Corporate Reputation Review 18 (3): 210-222.

Camilleri, MA and, Camilleri, AC (2018) The Performance Management and Appraisal in Higher Education. In Cooper, C. (Ed) Driving Productivity in Uncertain and Challenging Times, (ed C. 
Camilleri, MA (2019a) Measuring the corporate managers' attitudes toward ISO's social responsibility standard. Total Quality Management \& Business Excellence, 30(13-14): $1549-1561$.

Camilleri, MA (2019b) Higher Education Marketing: Opportunities and Challenges in the Digital Era. Academia, 0(16-17): 4-28.

Camilleri, MA and, Camilleri , AC (2019) The students' readiness to engage with mobile learning apps. Interactive Technology and Smart Education, 17(1): 28-38.

Cappiello G and Pedrini G (2017) The performance evaluation of corporate universities. Tertiary Education and Management 23(3): 304-317.

Cardoso S, Tavares O and Sin C (2015) The quality of teaching staff: higher education institutions' compliance with the European Standards and Guidelines for Quality Assurance- the case of Portugal. Educational Assessment, Evaluation and Accountability 27(3): 205-222.

Cederblom D (1982) The performance appraisal interview: A review, implications, and suggestions. Academy of Management Review 7(2): 219-227.

Chou CP and Chan CF (2016) Trends in publication in the race for world-class university: The case of Taiwan. Higher Education Policy 29(4): 431-449.

Cullen J, Joyce J, Hassall T and Broadbent M (2003) Quality in higher education: from monitoring to management. Quality Assurance in Education 11(1): 5-14.

Decramer A, Smolders C and Vanderstraeten A (2013) Employee performance management culture and system features in higher education: relationship with employee performance management satisfaction. The International Journal of Human Resource Management 24(2): 352-371.

Deem R (1998) 'New managerialism' and higher education: The management of performances and cultures in universities in the United Kingdom. International Studies in Sociology of Education 8(1): 47-70.

Deem R and Brehony KJ (2005) Management as ideology: The case of 'new managerialism' in higher education. Oxford Review of Education 31(2): 217-235.

Deem R, Mok KH and Lucas L (2008) Transforming higher education in whose image? Exploring the concept of the 'world-class' university in Europe and Asia. Higher Education Policy 21(1): 83-97.

DeNisi AS and Pritchard RD (2006) Performance appraisal, performance management and improving individual performance: A motivational framework. Management and Organization Review 2(2): 253-277. 
DeNisi A and Smith CE (2014) Performance appraisal, performance management, and firm-level performance: a review, a proposed model, and new directions for future research. Academy of Management Annals 8(1): 127-179.

Dill DD (1997) Higher education markets and public policy. Higher Education Policy 10(3-4): 167-185.

Dill DD and Soo M (2005) Academic quality, league tables, and public policy: A crossnational analysis of university ranking systems. Higher Education 49(4): 495-533.

Dilts DA, Haber LJ, Bialik D and Haber LJ (1994) Assessing What Professors Do: An Introduction to Academic Performance Appraisal in Higher Education (Vol. 61). Westport (CT). USA: Greenwood Publishing Group.

Dinham S (2005) Principal leadership for outstanding educational outcomes. Journal of Educational Administration 43(4): 338-356.

Enders J (2004) Higher education, internationalisation, and the nation-state: Recent developments and challenges to governance theory. Higher Education 47(3): 361-382.

Etzkowitz H, Webster A, Gebhardt C and Terra BRC (2000) The future of the university and the university of the future: evolution of ivory tower to entrepreneurial paradigm. Research Policy 29(2): 313-330.

Fadeeva Z and Mochizuki Y (2010) Higher education for today and tomorrow: university appraisal for diversity, innovation and change towards sustainable development. Sustainability Science 5(2): 249-256.

Gagné M and Deci EL (2005) Self-determination theory and work motivation. Journal of Organizational Behavior 26(4): 331-362.

Geuna A and Martin BR (2003) University research evaluation and funding: An international comparison. Minerva 41(4): 277-304.

Groenewald T (2004) A phenomenological research design illustrated. International Journal of Qualitative Methods 3(1): 42-55.

Herdlein R, Kukemelk H and Türk K (2008) A survey of academic officers regarding performance appraisal in Estonian and American universities. Journal of Higher Education Policy and Management 30(4): 387-399.

Heywood JS, Jirjahn U and Struewing C (2017) Locus of control and performance appraisal. Journal of Economic Behavior and Organization 142: 205-225.

Irwin P (2008) Competencies and employer engagement. Asia Pacific Education Review 9(1): 63-69. 
Jauhiainen A, Jauhiainen A, Laiho A and Lehto R (2015) Fabrications, time-consuming bureaucracy and moral dilemmas-Finnish University employees' experiences on the Governance of University Work. Higher Education Policy 28(3): 393-410.

Kanji GK, Malek A and Tambi BA (1999) Total quality management in UK higher education institutions. Total Quality Management, 10(1): 129-153.

Kaplan RS and Norton DP (1992) The Balanced Scorecard's Measures That Drive Performance. Putting the balanced scorecard to work. Harvard Business Review, January February: 71-79.

Kaplan RS and Norton DP (1995) Putting the balanced scorecard to work. In Shaw DG, Schneier CE, Beatty RW and Baird LS (Eds.) Performance measurement, Management, and Appraisal Sourcebook, pp. 66-74.

Kivistö J, Pekkola E and Lyytinen A (2017) The influence of performance-based management on teaching and research performance of Finnish senior academics. Tertiary Education and Management 23(3): 260-275.

Kohoutek J, Veiga A, Rosa MJ and Sarrico CS (2018) The European Standards and Guidelines for Quality Assurance in the European Higher Education Area in Portugal and the Czech Republic: Between the Worlds of Neglect and Dead Letters? Higher Education Policy 31(2): 1-24.

Kuvaas B (2006) Performance appraisal satisfaction and employee outcomes: mediating and moderating roles of work motivation. The International Journal of Human Resource Management 17(3): 504-522.

Lincoln YS, and Guba EG (1985) Establishing trustworthiness. Naturalistic Inquiry, 289327.

Lo WYW (2009) Reflections on internationalisation of higher education in Taiwan: perspectives and prospects. Higher Education 58(6): 733-745.

Lo WYW (2011) Soft power, university rankings and knowledge production: Distinctions between hegemony and self-determination in higher education. Comparative Education 47(2): 209-222.

Lo WYW (2014) Dimension 1: Influences of University Rankings: Changes in Policy, University Governance and Individual Behaviours. In University Rankings. Heidelberg: Springer, pp. 81-101.

Marginson S (2000) Rethinking academic work in the global era. Journal of Higher Education Policy and Management 22(1): 23-35.

Marginson S (2006) Dynamics of national and global competition in higher education. Higher Education 52(1): 1-39. 
Marginson S (2013) The impossibility of capitalist markets in higher education. Journal of Education Policy 28(3): 353-370.

McKenzie K and Schweitzer R (2001) Who succeeds at university? Factors predicting academic performance in first year Australian university students. Higher Education Research and Development 20(1): 21-33.

Olssen M and Peters MA (2005) Neoliberalism, higher education and the knowledge economy: From the free market to knowledge capitalism. Journal of Education Policy 20(3): 313-345.

Pace A (2015) The role of performance appraisal in further education: the case of a postsecondary college in Malta. Available at:

https://www.um.edu.mt/library/oar/handle/123456789/3087 (Accessed 25 November 2019).

QS Rankings (2019) World University Rankings Methodology. Available at:

(https://www.topuniversities.com/qs-world-university-rankings/methodology (Accessed 10 July 2019).

Ramsden P (1991) A performance indicator of teaching quality in higher education: The Course Experience Questionnaire. Studies in Higher Education 16(2): 129-150.

Salanova M, Agut S and Peiró JM (2005) Linking organizational resources and work engagement to employee performance and customer loyalty: the mediation of service climate. Journal of Applied Psychology 90(6): 1217-1227.

Smeenk S, Teelken C, Eisinga R and Doorewaard H. (2008) An international comparison of the effects of HRM practices and organizational commitment on quality of job performances among European university employees. Higher Education Policy 21(3): 323-344.

Subbaye R (2018) Teaching in academic promotions at South African universities: A policy perspective. Higher Education Policy 31(2): 245-265.

Taylor J and Baines C (2012) Performance management in UK universities: implementing the Balanced Scorecard. Journal of Higher Education Policy and Management 34(2): 111124.

Teelken C (2012) Compliance or pragmatism: How do academics deal with managerialism in higher education? A comparative study in three countries. Studies in Higher Education 37(3): 271-290.

THE (2019) The Times Higher Education World University Rankings explained. Available at: https://www.timeshighereducation.com/student/advice/world-university-rankings-explained (Accessed 10 July 2019). 
Umashankar V and Dutta K (2007) Balanced scorecards in managing higher education institutions: an Indian perspective. International Journal of Educational Management 21(1): 5467.

University of Texas (2019) Performance appraisals. Human Resources Service Center, Texas. Available at: https://hr.utexas.edu/manager/pm/performance-appraisals_(Accessed 23 November 2019).

Waring M (2013) All in this together? HRM and the individualisation of the academic worker. Higher Education Policy 26(3): 397-419.

Welch AR (1998) The cult of efficiency in education: Comparative reflections on the reality and the rhetoric. Comparative Education 34(2): 157-175.

Welch AR (2007) Blurred vision? Public and private higher education in Indonesia. Higher Education 54(5): 665-687.

Witte KD and López-Torres L (2017) Efficiency in education: a review of literature and a way forward. Journal of the Operational Research Society 68(4): 339-363.

Wood P and Salt J (2018) Staffing UK universities at international campuses. Higher Education Policy 31(2): 181-199.

Wu HY, Lin YK and Chang CH (2011) Performance evaluation of extension education centers in universities based on the balanced scorecard. Evaluation and Program Planning 34(1): 37-50.

\section{APPENDIX A}

\section{Interview Guiding Questions}

Generic Perspective: Describe your HEI's PA exercise? What PA measures are being implemented in your HEI? What are your views on your HEI's PA? Identify its strengths and weaknesses? 
Customer Perspective: Explain how would you describe your HEI's student-centered teaching? Is your HEI delivering quality education. Is it student-centric? What processes do you use to assess the needs and wants of your students? How do you monitor classroom performance? How would you address attendance problems? Are your students furthering their studies at your HEI? Are they finding employment after they graduate from your HEI?

Internal Perspective: Is your HEI focusing on improving the quality of its research output? Do you experience any pressures to publish articles in journals? Is your HEI supporting you in your research endeavors? Is your HEI investing in resources, technologies and infrastructures to improve the quality of its teaching and research?

Organizational Capacity Perspective: What were your professional development activities in the past year? Did you attend in-service courses? Where you involved in team planning, mentoring, collaborative work with colleagues? Did you attend academic conferences or industry gatherings? Explain how you applied the knowledge that you gained from your HEI's continuous professional development (CPD) programs. Did the students or others benefit from your CPD? Describe your HEIs' relationship with its external stakeholders?

Financial Perspective: How is your HEI improving its financial performance? Describe its sources of income. Can you identify what additional resources, technologies and infrastructures you would require to increase your performance? 